\title{
Multi-Teaching Styles Approach and Active Reflection: Effectiveness in Improving Fitness Level, Motor Competence, Enjoyment, Amount of Physical Activity, and Effects on the Perception of Physical Education Lessons in Primary School Children
}

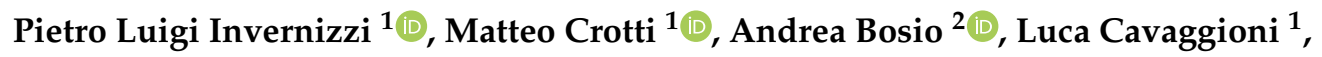 \\ Giampietro Alberti ${ }^{1}\left[\right.$ and Raffaele Scurati ${ }^{1, *(1)}$ \\ 1 Department of Biomedical Sciences for Health, Università degli Studi di Milano, 20129 Milan, Italy; \\ pietro.invernizzi1@unimi.it (P.L.I.); crotti.mc@gmail.com (M.C.); cavaggioni.luca@gmail.com (L.C.); \\ giampietro.alberti@unimi.it (G.A.) \\ 2 Human Performance Laboratory, Mapei Sport, 21057 Olgiate Olona (VA), Italy; andrea.bosio@mapeisport.it \\ * Correspondence: raffaele.scurati@unimi.it; Tel.: +39-02-5031-5161
}

Received: 16 November 2018; Accepted: 9 January 2019; Published: 15 January 2019

check for updates

\begin{abstract}
Physical education (PE) researchers sustain that the teaching styles adopted by PE teachers play a key role in defining children's positive experiences during lessons and have a relevant impact on their psychophysical health. However, a limited number of studies has examined the effect of teaching styles on these aspects. The aim of this study was to investigate the effectiveness of an integrated approach mainly based on integration of multi-teaching styles and active reflection (MTA) on the fitness level, motor competence, enjoyment, self-perception, amount of physical activity (PA), and children's perception of PE, in Italian primary school children. Participants were 121 children from three elementary schools. Children were randomly assigned into two groups: (a) an intervention group (IG) that received PE lessons based on MTA provided by specifically trained PE students, and (b) a control group (CG) that received standard PE lessons (S-PE) from primary school classroom teachers. Both groups engaged in two PE lessons per week lasting $1 \mathrm{~h}$ each for 12 weeks. The findings revealed an increase in the children's fitness level, motor competence, enjoyment and amount of PA in the IG compared to those in the CG. Furthermore, the children of the IG spent more time being engaged on a task, reflecting on it, and wasted less time during PE compared to the children of the CG. Finally, the children of the IG reported higher levels of satisfaction with PE lessons and teaching styles compared to children of the CG. Integration of different teaching styles lead by specifically trained educators can be suggested as a valuable strategy to provide learning experiences of children of primary school to have positive effects on their physical literacy development promoting healthy lifestyles.
\end{abstract}

Keywords: learning; integrated teaching styles; physical literacy; productive-reproductive styles; quantitative and qualitative research

\section{Introduction}

Low levels of physical activity (PA) and sedentary behaviour in youth are associated with cardio-metabolic diseases and obesity [1,2]. Moreover, childhood PA behaviours predict adulthood PA levels, with the most active and least sedentary students presenting higher levels of PA and lower body mass index later in life as compared to their peers. In view of these findings, the promotion of PA in childhood has been identified as a key strategy to tackle the problem obesity and chronic diseases [3]. 
Researchers [4] and the World Health Organization [5] suggested that school-based interventions could have a relevant impact on students' PA habits since students spend large amounts of their time in school. In particular, the concept of physical literacy has gained increasing interest and can be defined as an individual's level of competence, autonomy and responsibility concerning physical and sports activities in lifelong participation in PA [6,7]. In other words, and in practical terms, an individual is considered "physically literate" when he or she:

- can learn abilities required to practice a great variety of PA;

- engages in PA regularly;

- knows the benefits of PA and the negative effects of the hypokinetic syndrome, giving the right value to what is done.

Four main social spheres can describe the interest of individuals towards the practice of PAs: sport (associate with sport competition), health (associated with movement as a medicine), school (associated with education), and mass media (associated with behaviors coming from trends of the moment or sport exhibitions). Despite these four spheres underpin the awareness of PA importance, studies draw attention to the low participation of young people to sport activities and an to an overall poor motor competence in children [8], together with an early decline of PA during childhood [9].

In view of what is exposed, high-quality multi-teaching approaches (MTAs) in PE could positively impact children's physical literacy journey and consequently their future health [7]. Physically literate children are more likely to become adults, who take part in PA during their lifetime and consequently experience good physical, social, mental and physical health compared to individuals who do not engage in PA $[10,11]$. An increasing amount of physically literate individuals in the population might lead to a decrease of public expenses in treatment of non-communicable diseases, representing a considerable cost for our society [12].

We therefore suggest that promoting high-quality MTAs in physical education (PE) could represent a sustainable approach to prevent healthcare expenses for the public. PE at school has been identified as a key setting to promote physical literacy, given that it is the only opportunity to engage a large number of students in education about PA at a population level [13].

Stodden et al. [14] and Robinson et al. [15] reported that PA behaviours and the risk of obesity are influenced by the interaction of motor competence, self-perception, and fitness level. These aspects should be developed using the best practices [16] to promote healthy lifestyles. This may be accomplished by highly trained personnel. Unfortunately, in some countries PE interventions are entrusted to primary school classroom teachers who do not hold specific PE competences and might not adopt specific and appropriate teaching approaches.

Teaching methods or teaching styles play a central role in influencing students' experiences during PE lessons. Mosston and Ashworth [17] described the variety of teaching styles along what they called a "spectrum of teaching styles" with reproduction (learners reproduce what the teacher proposes) and production (learners are free to discovers new solutions to solving motor problems) styles at the opposite ends of the spectrum (see Section 2.1.7, Table 1).

Previous research reported that the reproduction teaching style is the most common approach and that it is widely used in PE [18-20]. Some reproduction teaching styles (e.g., command, and practice) are mainly based on learning by imitation of models of movement, and they are effective when working on complex tasks, cardiorespiratory fitness and/or in conditions presenting high emotional involvement $[17,21]$. These styles are useful, in particular, when more organized and controlled tasks are required to guarantee success and safety of all performers $[17,22]$. However, command and practice teaching styles may fail to value individual learner characteristics, ideas, and individual needs [23].

Differently, a production teaching style may lead to positive engagement and enjoyment during PE lessons because it involves students in decision-making processes and focuses on cognitive, social, and personal development [24]. A production teaching approach such as "Guided Discovery" has been found to foster a better motivational climate and more adaptive cognitive and affective responses in 
secondary school students during PE lessons compared to reproduction styles [25]. Byra [22] reported: "the productive cluster is dependent upon the learner producing new knowledge to self or teacher. In a productive teaching style, the teacher invites learners to engage in cognitive operations like problem-solving, creating, inventing or critical thinking to discover new movements".

The problem-based learning or problem-solving learning process works towards understanding or resolving problems [26]. This strategy promotes engagement through active reflection [27] and the children are spurred to explore, discover, and find new and different solutions [28]. Despite belonging to the reproduction styles, some teaching styles such as reciprocal, self-check and inclusion present cognitive and affective features similar to the production styles like problem-solving and guided discovery [22]. In these styles, the task, despite being pre-established, provides a certain freedom of action, choice and assessment [28].

Collaborative learning is another effective strategy to foster motivation. In collaborative learning, teachers do not provide all the information needed to complete a task but direct students to the information sources, facilitating learning through discussion and workgroup activities [29]. It can be considered as a guided discovery or problem-solving performed by the whole group, which acts in a convergent or divergent production approach.

Questioning strategy is a way to stimulate the learners' cognitive functions in both reproductive and productive situations through a reflective approach based on the conscious analysis of the benefits arising from the activity performed [25,30]. In particular, when reproductive styles are applied, questions allow the learner to verify his comprehension of the received instructions [31] and enhance the cognitive function related to the memory capacity and mental representation of a movement model [17,32]. In productive styles, answering questions allow for the learner's creativity of making original movements and learning autonomy [22].

Therefore, the combination of multi-teaching styles, thanks to their specific and different characteristics, can represent the ideal approach to better developing physical literacy to promote healthy lifestyles.

The aim of the present study was to compare the effects of an integration of MTA based on active reflection to standard PE practice (S-PE) on some essential features of physical literacy (physical fitness, amount of PA, motor competence, self-perception, and enjoyment). PE lessons taught according to MTA were provided by graduate PE students while PE lessons taught by S-PE were provided by primary school classroom teachers.

We hypothesized that an integrated approach mainly based on a combination of teaching styles could be more effective for fitness and motor competence development, enjoyment and to increase the amount of PA performed outside the school context than the standard PE practice. Qualitative and quantitative methods were used to assess these constructs.

\section{Materials and Methods}

Three primary schools within the province of Milan, Italy provided informed gatekeeper consent for participation in the study. Written, informed parental consent to participate in the study was obtained for 121 fifth-grade students (age, $10.5 \pm 0.5$ years) from two classes per school leading to a total of six classes. Children and parents could withdraw participation at any time point. The classes were randomly assigned to an intervention group (IG) or a control group (CG): 62 pupils were allocated to the IG (29 girls, 33 boys: height, $143 \pm 0.06 \mathrm{~cm}$; body mass, $38.08 \pm 7.2 \mathrm{~kg}$; BMI, $18.5 \pm 2.7 \mathrm{~kg} / \mathrm{m}^{2}$ ) and 59 to the CG (35 girls, 24 boys: height, $144 \pm 0.07 \mathrm{~cm}$; body mass, $41.1 \pm 8.7 \mathrm{~kg}$; BMI, $18.9 \pm$ $3.0 \mathrm{~kg} / \mathrm{m}^{2}$ ). There were no differences in anthropometrics between the two groups at baseline. None of the children presented health conditions or contraindications for exercise testing that could impair regular participation in PE lessons. The teacher-children ratio per class was on average 1:20. The study was approved by the local Institutional Review Board in accordance with the Helsinki Declaration.

The IG followed a PE program based on MTA, comprising guided discovery, problem-solving, collaborative learning strategies, direct application of instruction and tasks demand, and answering 
questions about the activity performed which emphasize positive engagement in PA exercises to induce children's autonomy in motor practice. The program was conducted by three graduate PE students (attending the last year of the Master of Science in Sport and Exercise Science at the University of Milan, with no experience in teaching PE in the primary school), one per each IG class, $2 \mathrm{~h}$ a week for 12 weeks. During the same period, the CG received $2 \mathrm{~h}$ a week of S-PE lessons provided by three primary school classroom teachers (with a minimum of fifteen years expertise in primary school teaching). In Italy, primary school teachers have strong theoretical and didactic knowledge on teaching in a large number of subjects, including PE. Conversely, they have a reduced practical experience in PE practice coming from their education programs compared to PE students, which have in their education a wider practical experience in exercise sciences and in leading PE but a little specific didactic knowledge on teaching in primary schools.

The main learning objectives, for both IG and CG, respected the goals defined by national indications established in the Italian curriculum for primary schools [33].

CG teachers did not receive any specific instruction, whereas before the intervention, IG's PE students attended three 2 - $\mathrm{h}$ training sessions with the research team following specific guidelines based on MTA.

In detail, lessons of IG were designed following a didactic sequence of four blocks of six lessons each: two structured blocks (the operative guidelines and lessons were designed in detail by the authors of the present research), one quasi-structured block (the operative guidelines were provided by the authors while the lessons were designed by the PE students), one free block (fully designed by the PE students according to the MTA method proposed in the previous blocks). Meetings with the PE students were held at the end of each block to summarize the effectiveness of the lessons and to revise and adapt the next lessons, if necessary.

The pedagogical principles guiding the lesson planning in the IG's PE program were inspired by Chróinín, et al. [34], and were divided into five key points: (i) promote social interaction with a positive participation among students; (ii) stimulate and involve students in activities which are suitable for them (neither too difficult, nor too easy); (iii) increase motor competence by involving opportunities for motor learning and fitness improvement during each activity and by providing information and engaging in reflection about physical exercises usefulness and their practice outside the school context; (iv) develop a positive, fun and enjoyable setting based on satisfaction in improving and learning new skills; (v) experience a pleasant experience during PE lessons as a result of a positive children's engagement and commitment (mastery climate).

\subsection{Testing Procedures}

Baseline and post-intervention data on the cardiorespiratory fitness level, motor competence, self-perception, enjoyment and the amount of PA performed outside the school context were collected by the same trained researcher using a standardized protocol (time of day, location, and testing order). Participants were familiarized with the assessment procedure before data collection. In addition, a qualitative assessment of the study outcomes was performed using semi-structured interviews and video analysis.

\subsubsection{Physical Fitness Level}

The physical fitness level was assessed using the Multistage Fitness Test (MFT) [35]. The MFT consists of a shuttle run test in which subjects run between two lines set $20 \mathrm{~m}$ apart, starting at a running speed of $8 \mathrm{~km} / \mathrm{h}$, with increments of $0.5 \mathrm{~km} / \mathrm{h}$ per minute until exhaustion. A recorded audiotape was used to pace the running speed during the test. Children were encouraged to perform at their best; only completed 20-m shuttle runs were considered for analysis. The MFT was followed by a 5 -min cool down with stretching activities. 


\subsubsection{Motor Competence}

Motor competence was assessed using the Test of Gross Motor Development (TGMD-2) [36]. The test evaluates 12 motor skills under two categories: locomotor skills (running, jumping, leaping, galloping, sliding, and hopping) and object control skills (striking, bouncing, kicking, under-over hand throwing, and catching). The TGMD-2 applies multiple criteria to score skills performance. The sum of locomotor and object control skills scores returns a total skill score. The TGMD-2 has a high inter-rater reliability using inter-class correlation coefficients (ICCs) (ICC: object control, 0.93; catch, 0.71; kick and throw: 0.80) [37] and validity [38].

\subsubsection{Self-Perception}

Self-perception was assessed using the Self-Description Questionnaire (SDQ) [39]. The SDQ is a 76-item self-report questionnaire that provides a multidimensional/hierarchical measure of the children's self-concept [40]. It is organized into 11 subscales in three domains: academic, non-academic, and global. Each item is rated on a Likert-type scale with a scoring system profile.

\subsubsection{Enjoyment}

Rating of perceived enjoyment was quantified using the Physical Activity Enjoyment Scale (PACES) questionnaire [41]. The PACES contains 16 items rated on a 5-point bipolar Likert-type scale from 1 ("Disagree a lot") to 5 ("Agree a lot"). The total score ranges from 16 to 80, with higher scores indicating better perceived enjoyment. The PACES is a reliable (Cronbach alpha values: 0.78-0.89), valid tool to assess PA enjoyment in older children [41,42].

\subsubsection{Amount of Physical Activity}

The PA volume was evaluated using the Physical Activity Questionnaire for Older Children (PAQ-C). The PAQ-C is a 10-item questionnaire that investigates weekly PA in children [43]. The tool requires children to recall their participation in PAs over the previous 7 days and to rate the level of PA on a Likert-type scale from 1 to 5 showing a high reliability (males: 0.80 , females: 0.83 ).

\subsubsection{Children's Perception of PE Lessons and of Primary School Classroom Teachers or PE Students}

After the quantitative analysis, differences emerged between IG and CG. Therefore, to further analyze the effect on the results coming from MTA and S-PE approaches, a qualitative analysis of children's perception of PE lessons and of their educator was conducted by means of semi-structured interviews on a sample of children [44]. Twenty-eight children (14 from the IG, and 14 from the CG) were randomly selected and interviewed. They answered four questions regarding their perceived level of satisfaction about the PA and the primary school classroom teacher or PE students who conducted the lessons ("Regarding the last 3 months of PE lessons, what did you enjoy most?"; "Regarding the last 3 months of PE lessons, what did you enjoy least?"; "Regarding the last 3 months of PE lessons, which were the educator's positive traits?"; "Regarding the last 3 months of PE lessons, which were the educator's negative traits?"). Data were collected by three external interviewers and were analyzed identifying a coding process [45]. From the semi-structured interviews, emergent features of children's perception appeared and were analyzed. Firstly, a line-by-line coding procedure to originate specific labels was done; secondly, common labels were created and counted; lastly, the relationship between each category was done, creating a diagram according to the grounded theory method [46]. 


\subsubsection{Primary School Classroom Teachers and PE Students' Self-Perception of Teaching Styles}

At the end of the study the primary school classroom teachers and PE students completed a semi-structured questionnaire investigating their self-perception of teaching styles based on Mosston's classification [17]. They were asked to report whether they had adopted or not a productive or a reproductive style from a list of teaching styles (Table 1). The list contained the key points to allocate the teaching approach that the primary school classroom teachers and PE students believed they used during the lessons. Ten scenarios provided a mutually exclusive images presenting the essential characteristics of the different teaching styles [47]. Primary school classroom teachers and PE students were asked to answer how often they used a definite teaching style during their lessons. They were asked to rate on a Likert scale (1-5) how often they used each teaching style (not at all, minimally; here \& there; often; most of time). In case the teacher rated "here \& there; often; most of time", a positive answer "YES" was considered while a negative answer "NO" was considered when the teacher rated "not at all or minimally" [48].

Table 1. Teaching styles (Mosston \& Ashworth [17], adapted).

\begin{tabular}{|c|c|c|}
\hline & Teaching style & Description \\
\hline \multirow{5}{*}{ Reproductive Styles } & Command & $\begin{array}{l}\text { The teacher makes all decision and pupils act when the teacher } \\
\text { is told to. }\end{array}$ \\
\hline & Practice & $\begin{array}{l}\text { The teacher describes or demonstrates a task, and the pupils } \\
\text { practice at their own pace. }\end{array}$ \\
\hline & Reciprocal & $\begin{array}{l}\text { The teacher describes or demonstrates a task, and the pupils } \\
\text { practice in pairs, helping each other. }\end{array}$ \\
\hline & Self-check & $\begin{array}{l}\text { The teacher presents a task. The pupils practice at their own } \\
\text { pace, evaluating and being responsible of their } \\
\text { task performance. }\end{array}$ \\
\hline & Inclusion process & $\begin{array}{l}\text { The teacher models a task at different levels of difficulty. } \\
\text { The pupils have to choose their most comfortable level. }\end{array}$ \\
\hline \multirow{5}{*}{ Productive styles } & Guided discovery & $\begin{array}{l}\text { The teacher ask questions or sets physical problems addressed } \\
\text { to guide the pupils to discover a successful skill. }\end{array}$ \\
\hline & Problem-solving & $\begin{array}{l}\text { The teacher asks questions or sets physical problems to which } \\
\text { pupils have to find a solution to perform (divergent discovery). }\end{array}$ \\
\hline & Individual-based choice & $\begin{array}{l}\text { The teacher sets the subject. The pupils have to plan and } \\
\text { perform the practice on the given subject. }\end{array}$ \\
\hline & Learner-initiated & $\begin{array}{l}\text { The teacher sets the subject. The pupils have to plan and } \\
\text { perform the practice on the given subject. The teacher helps } \\
\text { when being asked for and evaluating the results. }\end{array}$ \\
\hline & Self-teaching & $\begin{array}{l}\text { The teacher supervises, but the activity is totally managed by } \\
\text { the pupils themselves. }\end{array}$ \\
\hline
\end{tabular}

\subsubsection{Video Analysis of the PE Lessons}

To assess the salient features of each PE lesson (total time, action time, resting time, time dedicated to personal reflection, and duration of teaching style), one lesson per teaching block was randomly selected and video recorded in both groups for subsequent video analysis.

Records were analysed and evaluated twice by three PE experts using the Instrument for Identifying the Teaching Styles (IFITS) [49]. Didactic behaviours during the lessons were assessed. The experts were trained for $6 \mathrm{~h}$ to learn how to collect data and how to operate with coding instruments.

\subsection{Statistical Analysis}

Statistical analyses of the quantitative data were performed using the Statistical Package for Social Sciences (SPSS version 20.0, IBM Corp., Armonk, NY, USA). All data are presented as means $\pm \mathrm{SD}$. Normal distribution of the raw data of each variable was assessed by applying the Kolmogorov-Smirnov test. A series of one-way analysis of covariance (ANCOVA) using BMI, gender and baseline values as covariates was used to assess the differences between groups for MFT, TGMD-2, SDQ, PAQ-C, and PACES pre-post-intervention difference (delta between baseline 
and post-intervention). In addition, Eta Squared $\left(\eta^{2}\right)$ statistics was used to calculate the magnitude of difference between the groups. The thresholds of small, moderate, and large effects were defined as $0.01,0.06$, and 0.14 , respectively [50]. The Mann-Whitney $\mathrm{U}$ test was used to estimate between-group differences in lesson duration and parameters of the teaching methods. The level of significance was set at $p<0.05$.

\section{Results}

Table 2 presents the results of analysis of covariance (ANCOVA) using BMI, gender and baseline values as covariates to assess pre- vs post-intervention differences in each test.

\subsection{Physical Fitness Level}

The MFT VO2max estimate increased by $1.38 \mathrm{~mL} / \mathrm{kg} / \mathrm{min} \pm 0.88(95 \% \mathrm{CI})$ more in IG than in CG, with a moderate eta squared $\left(p=0.002, \eta^{2}=0.09\right)$ (IG: $45.29 \pm 3.2 \mathrm{~mL} / \mathrm{kg} / \mathrm{min}$ pre-intervention vs. $47.68 \pm 9.2 \mathrm{~mL} / \mathrm{kg} / \mathrm{min}$ post-intervention; CG: $45.20 \pm 3.5 \mathrm{~mL} / \mathrm{kg} / \mathrm{min}$ pre-intervention vs. $46.30 \pm$ $3.8 \mathrm{~mL} / \mathrm{kg} / \mathrm{min}$ post- intervention).

\subsection{Motor Competence}

TGMD-2 significantly increased by $5.44 \pm 2.36 \mathrm{AU}(95 \% \mathrm{CI})$ more in IG compared to that in CG with a large eta squared $\left(p<0.001, \eta^{2}=0.17\right)$ (IG: coordination, $75.6 \pm 14.5 \mathrm{AU}$ pre-intervention vs. $81.3 \pm 12.4 \mathrm{AU}$ post-intervention; object control, $35.5 \pm 1.2 \mathrm{AU}$ pre-intervention vs. $39.0 \pm 1.0 \mathrm{AU}$ post-intervention; locomotion, $40.1 \pm 0.9 \mathrm{AU}$ pre-intervention vs. $42.3 \pm 0.8 \mathrm{AU}$ post-intervention). No changes in TGMD-2 were noted for the CG $(-0.12 \pm 1.68 \mathrm{AU}(95 \% \mathrm{CI})$; coordination: $79.0 \pm 2.2 \mathrm{AU}$ pre-intervention vs. $78.5 \pm 2.0 \mathrm{AU}$ post-intervention; object control: $37.9 \pm 1.3 \mathrm{AU}$ pre-intervention vs. $36.6 \pm 1.2 \mathrm{AU}$ post-intervention; locomotion: $41.0 \pm 1.1 \mathrm{AU}$ pre-intervention vs. $41.9 \pm 0.9 \mathrm{AU}$ post-intervention).

\subsection{Self-Perception}

No significant changes ( $p=0.568$ ) were observed for both groups (IG: $3.6 \pm 0.4$ AU pre-intervention vs. $3.7 \pm 0.5 \mathrm{AU}$ post-intervention; $\mathrm{CG}: 3.6 \pm 0.4 \mathrm{AU}$ pre-intervention vs. $3.7 \pm 0.4 \mathrm{AU}$ post-intervention).

\subsection{Enjoyment}

A significant difference with a very large eta squared $\left(p<0.001, \eta^{2}=0.96\right)$ was found between the two groups for the PACES questionnaire results with the IG group presenting a score of $0.18 \pm 0.09$ $(95 \% \mathrm{CI})$ higher than CG. This indicated a significant change in PA enjoyment scores in the IG $(+2.92 \%$, $4.4 \pm 0.6 \mathrm{AU}$ pre-intervention vs. $4.5 \pm 0.4 \mathrm{AU}$ post-intervention) as compared to the $\mathrm{CG}(4.3 \pm 0.5 \mathrm{AU}$ pre-intervention vs. $4.3 \pm 0.3 \mathrm{AU}$ post-intervention).

\subsection{Amount of Physical Activity}

PAQ-C scores increased by $0.35 \pm 0.22 \mathrm{AU}(95 \% \mathrm{CI})$ more in IG than in CG $\left(p=0.002, \eta^{2}=0.09\right)$. This indicated a positive change in the PA volume between baseline and week 12 for the IG ( $2.6 \pm 0.5 \mathrm{AU}$ pre-intervention vs. $3.2 \pm 0.6 \mathrm{AU}$ post-intervention) as compared to the CG ( $2.8 \pm 0.6 \mathrm{AU}$ pre-intervention vs. $2.9 \pm 0.6 \mathrm{AU}$ post-intervention). 
Table 2. One-way analysis of covariance (ANCOVA) of the selected features.

\begin{tabular}{|c|c|c|c|c|c|c|c|c|}
\hline & \multicolumn{3}{|c|}{ Main Effect } & \multicolumn{5}{|c|}{ Pairwise Comparison } \\
\hline & \multicolumn{3}{|l|}{ Group } & \multirow{2}{*}{$\begin{array}{c}\text { Mean Diff (I-J) } \\
I G-C G\end{array}$} & \multirow{2}{*}{$S E$} & \multirow{2}{*}{ Sig. } & \multicolumn{2}{|c|}{ 95\% Confidence Int. (CI) } \\
\hline & $F$ & $p$-Value & $\eta^{2}$ & & & & $\begin{array}{l}\text { Lower } \\
\text { Bound }\end{array}$ & $\begin{array}{l}\text { Upper } \\
\text { Bound }\end{array}$ \\
\hline $\begin{array}{l}\text { Multistage Fitness Test } \\
\text { (MFT) }\end{array}$ & 9.732 & 0.002 & 0.09 & $1.383 *$ & 0.443 & 0.002 & 2.262 & 0.503 \\
\hline $\begin{array}{c}\text { Test of Gross Motor } \\
\text { Development (TGMD-2) }\end{array}$ & 20.865 & $<0.001$ & 0.17 & $5.441 *$ & 1.191 & $<0.001$ & 7.804 & 3.077 \\
\hline $\begin{array}{c}\text { Self-Description } \\
\text { Questionnaire (SDQ) }\end{array}$ & 0.328 & 0.568 & 0.00 & 0.039 & 0.068 & 0.568 & 0.175 & -0.096 \\
\hline $\begin{array}{c}\text { Physical Activity } \\
\text { Enjoyment Scale (PACES) }\end{array}$ & 193.690 & $<0.001$ & 0.96 & 0.190 * & 0.080 & 0.020 & 0.349 & 0.031 \\
\hline $\begin{array}{l}\text { Physical Activity } \\
\text { Questionnaire for Older } \\
\text { Children (PAQ-C) }\end{array}$ & 10.029 & 0.002 & 0.09 & $0.345^{*}$ & 0.109 & 0.002 & 0.561 & 0.129 \\
\hline
\end{tabular}

IG denotes the intervention group. CG denotes the control group; SE denotes the standard error.

\subsection{Children's Perception of PE Lessons and of Primary School Classroom Teachers and PE Students}

Figures 1 and 2 show the results of the qualitative analysis of the semi-structured interviews about perception of the PE lessons. The responses highlight that free play and games were the activities preferred by the CG (78.6\%). Differently, only $35.7 \%$ of the IG children preferred games, while $64.3 \%$ were more in favour of newly learned exercises during PE lessons and the knowledge acquired. In particular, $42.9 \%$ of the children enjoyed endurance training performed (the "little train" circuit course, in particular).

The CG reported dissatisfaction with frequent quarrelling while playing $(28.6 \%)$ and with such exercises (28.6\%) as jumping rope, football, and endurance running, and other activities they considered repetitive $(28.6 \%)$. Though $64.3 \%$ of the IG children reported no dissatisfaction with the PA program content, $35.7 \%$ of them reported they were dissatisfied because they wanted to play games such as basketball or because they would have liked to play dodgeball more frequently.

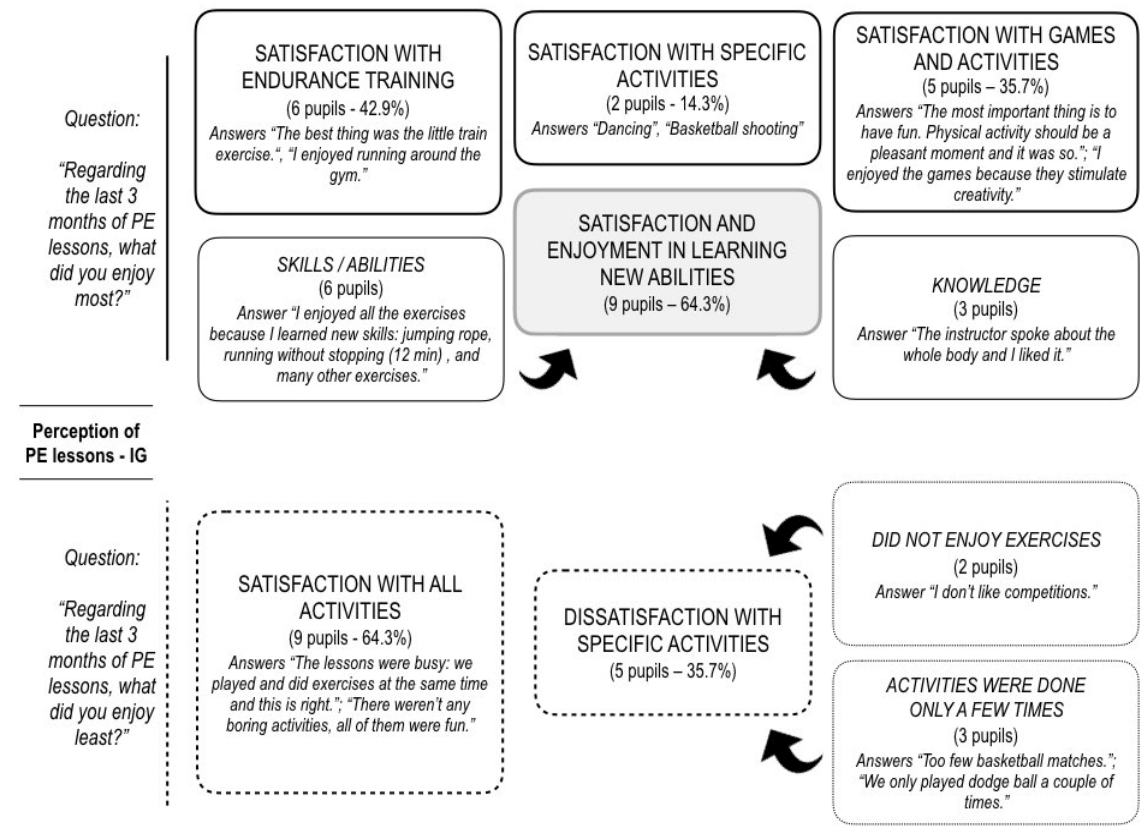

Figure 1. Semi-structured interview responses from the IG children about their perception of the PE lessons. 


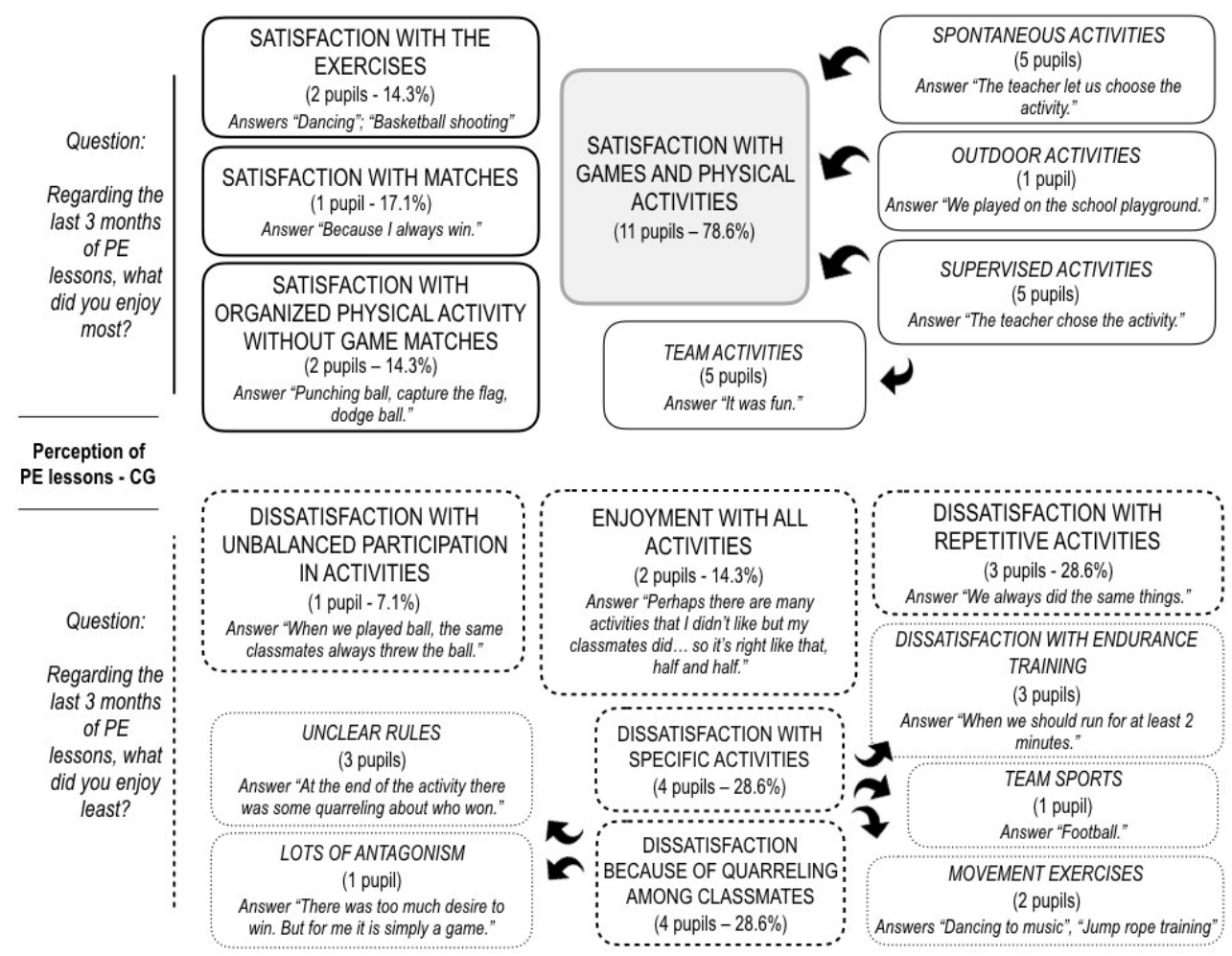

Figure 2. Semi-structured interview responses from the CG children about their perception of the PE lessons.

Figures 3 and 4 show the way children perceived the primary school classroom teachers and PE students: $71.4 \%$ of the CG children appreciated their primary school classroom teachers' kindness and intelligence; $28.6 \%$ appreciated the games the primary school classroom teachers selected. Conversely, $78.6 \%$ of the IG children liked the PE students for their teaching skills. In particular, they appreciated the PE students' ability to explain activities clearly, enforce game rules, and provide encouragement to excel.

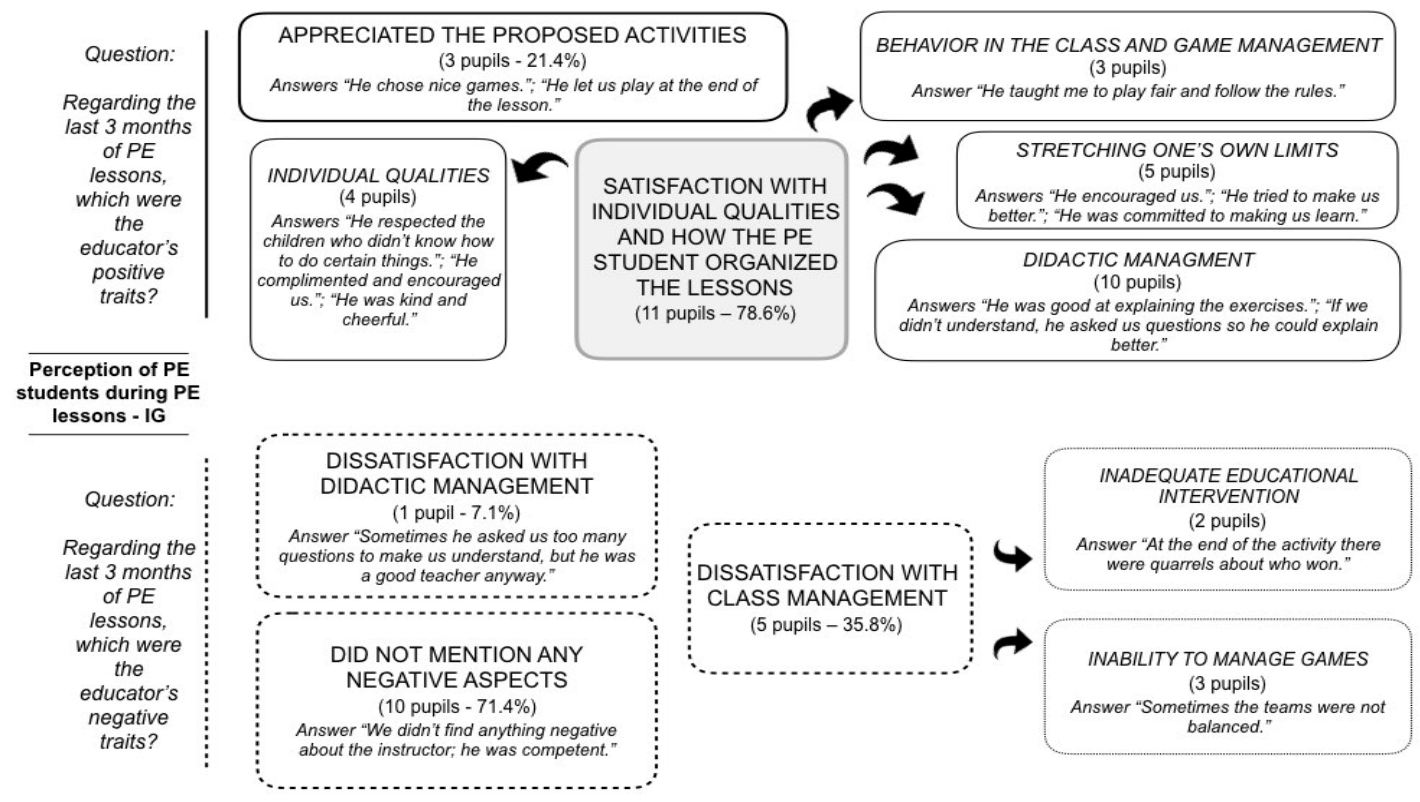

Figure 3. Semi-structured interview responses from the IG children about their perception of PE students during PE lessons. 
While $28.6 \%$ of the CG children did not report negative aspects about the primary school classroom teachers, $28.6 \%$ thought that the primary school classroom teacher was unable to manage the PE class in the gym and enforce the game rules, and another $28.6 \%$ stated that the primary school classroom teacher did not give adequate importance to PE (e.g., gleaned from the response: "The teacher used the PE lesson as a break."). While $71.4 \%$ of the IG children did not highlight any negative features about the PE students, 35.8\% complained that the PE students failed to manage disruptive behaviours or activities (e.g., gleaned from the responses: "if we did not pay attention, the educator got angry.", and "sometimes the teams were not balanced during the games.").

\subsection{Primary School Classroom Teachers' and PE Students' Self-Perception of Teaching Styles}

All of the PE students (IG) responded that they used the "problem-solving" and "guided discovery" categories of production teaching styles (Table 3). Differently, $66.7 \%$ of the primary school classroom teachers (CG) stated they used "guided discovery" and "individual-based choice", with all of them responding that they used a "learner-initiated" approach. As concerns about the reproduction teaching styles, $66.7 \%$ of the PE students (IG) reported they used "command" style, and all of them stated they used "practice", "reciprocal", and "inclusion process" teaching styles. All the primary school classroom teachers (CG) stated that they used "command", "practice", and "inclusion process" teaching styles, while $66.7 \%$ of them stated they also used the "reciprocal" style.

\subsection{Video Analysis of the PE Lessons}

The ICC was first applied to the results and showed an intra-rater reliability values of $0.90,0.98$, 0.96 and 1.00 for resting time, reflection time, in action time and total time activity, respectively.

As concern about the inter-rater reliability, values of $0.75,0.96,0.95$, and 1.00 were observed for resting time, action time, reflection time and total time, respectively.

As regards the teaching styles adopted, the intra-rater reliability analysis showed values of 0.82 for command style, 1.00 for practice, 0.97 for reciprocal, 0.99 for self-check, 1.00 for the inclusion process, 0.94 for guided discovery, 0.88 for problem-solving, 1.00 for individual-based choice, 0.78 for learner-initiated, and 1.00 for self-teaching.

Furthermore, the inter-rater reliability was 0.69 for the command style, 0.99 for practice, 0.97 for the reciprocal style, 0.97 for the self-check style, 0.99 for the inclusion process, 0.89 for guided discovery, 0.82 for problem-solving, 1.00 for individual-based choice, 0.71 for learner-initiated and 1.00 for self-teaching.

Video analysis of the PE lessons (Table 4) showed that the IG children spent more time doing PE than the CG children (+26.8\%). During PE, the majority of time was spent in action $(78.9 \%$ and $72.3 \%$ for IG and CG, respectively). The IG were inactive for a very limited amount of time $(3.9 \%)$, whereas the CG rested longer (27.7\%). No reflection time was observed in the CG.

With regard to the duration of production teaching styles during the PE lessons (Table 5), the IG used "guided discovery" and "problem-solving" (60.4\% and 39.6\%, respectively) while the CG only used "learned-initiated" style (100\%). Concerning the reproduction teaching styles, the "command" and the "reciprocal" were the two styles most often used in the IG (39.5\% and 26.7\%, respectively), while only the "command" style was used in the CG $(100 \%)$.

The percentage of the type of the activity refers to the total duration of the PE activity (total time activity, in minutes); IG denotes the intervention group (taught by PE students); CG represents the control group (taught by primary school classroom teachers). 
Table 3. Questionnaire responses from the primary school classroom teachers and PE students about their self-perception of the teaching styles they adopted during PE lessons.

\begin{tabular}{cccccc}
\hline \multirow{2}{*}{ Teaching Style } & \multicolumn{2}{c}{ IG } & \multicolumn{2}{c}{ CG } \\
\cline { 3 - 6 } & & Yes (\%) & No (\%) & Yes (\%) & No (\%) \\
\hline \multirow{3}{*}{ Reproduction } & Command & 66.7 & 33.3 & 100.0 & 0.0 \\
teaching styles & Practice & 100.0 & 0.0 & 100.0 & 0.0 \\
& Reciprocal & 100.0 & 0.0 & 66.7 & 33.3 \\
& Self-check & 33.3 & 66.7 & 33.3 & 66.7 \\
& Inclusion process & 100.0 & 0.0 & 100.0 & 0.0 \\
\hline \multirow{2}{*}{ Production } & Guided discovery & 100.0 & 0.0 & 66.7 & 33.3 \\
teaching styles & Problem-solving & 100.0 & 0.0 & 33.3 & 66.7 \\
& Individual-based choice & 33.3 & 66.7 & 66.7 & 33.3 \\
& Learner-initiated & 33.3 & 66.7 & 100.0 & 0.0 \\
& Self-teaching & 0.0 & 100.0 & 33.3 & 66.7 \\
\hline
\end{tabular}

IG denotes intervention group (taught by PE students); CG denotes the control group (taught by primary school classroom teachers).

Table 4. Duration of activities (in percentage), as measured in the video analysis of the PE lesson recordings.

\begin{tabular}{cccc}
\hline Activity & IG & CG & IG vs. CG (variation \%) \\
\hline Total time activity (min) & $56.8 \pm 2.8$ & $44.8 \pm 11.5$ & +26.8 \\
Resting time & 3.9 & 27.7 & \\
In action time & 78.9 & 72.3 & \\
Reflection time & 17.2 & 0.0 & \\
\hline
\end{tabular}

Plus-minus values are means \pm standard deviation (SD).

Table 5. Duration of teaching styles (in percentage) in the PE lessons, as measured by video analysis of PE lesson recordings.

\begin{tabular}{lccc}
\hline & Teaching Style & IG & CG \\
\hline Reproduction teaching styles & Command & 39.5 & 100 \\
& Practice & 15.1 & 0.0 \\
& Reciprocal & 26.7 & 0.0 \\
& Self-heck & 2.1 & 0.0 \\
& Inclusion process & 16.6 & 0.0 \\
\hline Production teaching styles & Guided discovery & 60.4 & 0.0 \\
& Problem-solving & 39.6 & 0.0 \\
& Individual-based choice & 0.0 & 0.0 \\
& Learner-initiated & 0.0 & 100 \\
& Self-teaching & 0.0 & 0.0
\end{tabular}

Plus-minus values are means \pm standard deviation (SD). IG denotes intervention group (taught by PE students); CG represents the control group (taught by primary school classroom teachers).

The percentages of teaching styles refer to the reproduction or to the production teaching approach.

\section{Discussion}

The results suggest that MTA, based on multiple and reflective styles (command, practice, reciprocal, self-check, inclusion process, guided discovery, and problem-solving) could provide a more positive overall experience of PE in primary school children, along with a higher level of physical fitness, motor competence, enjoyment, amount of PA and positive perceptions of lessons compared to S-PE, and there was a frequent use of only two teaching styles (command and learner-initiated) without use of questioning and reflection practice. 


\subsection{Physical Fitness Level and Motor Competence}

One of the main findings of this study is an improvement in cardiorespiratory fitness in the IG children. Among the activities the IG children engaged in, the "little train" circuit course was a cardiorespiratory exercise that lasted between 3 and $12 \mathrm{~min}$. In this context, the use of exercises based on command and practice styles, to provide opportunities for continuous and progressive practice, allowed for a better training load manipulation in terms of stimulus' intensity, frequency and duration. This is in line with the study of Jarani et al. [21] that showed how exercise-based PE structured in station/circuit (practice style) provided an adequate stimulus in improving cardiorespiratory fitness and was more effective than games.

Furthermore, the "little train" circuit run combines cardiorespiratory exercise with self-reflection. This mixed physical and cognitive task is a key strategy to foster motivation, which is necessary to preserve adequate intensity levels during cardiorespiratory fitness activities [51]. This strategy, combined with the increase of PA executed outside the school context (see the results of PA), could be the main reason for the improved cardiorespiratory fitness levels. As a matter of a fact, previous research showed that the amount (quantity) of PA regularly done is a key factor in improving physical fitness in children [52]. However, we cannot exclude that physical fitness improved to a greater extent in the IG group compared to CG simply because in the former group the students underwent a higher volume of endurance activities. This might represent a potential limitation for this particular aspect of the present study. A more appropriate comparison matching the volume of endurance activities should be done in future studies.

Another important finding is the greater improvement in motor competence observed in TGMD-2 in the IG compared to that in the CG $(+7.8 \%)$. We believe that activities, based on guided discovery, resolution problems, reciprocal, inclusion, self-check, which require students' critical thinking and involve the children in a significant amount of decision-making, as suggested by some authors [17,22], may have determined an optimal level of stimulus for promoting motor competence development. This is in line with the perspective of the challenge point framework, wherein the movement is a problem to solve and the task difficulty is determined by the interaction between the amount of information available to the learner and his/her capacities to collect and analyse it [53].

Our findings are in line with Pesce et al. [54,55] showing that the integration of motor and cognitive tasks, and a wide range of PE stimuli based on multifaceted tasks accommodating individual skill differences may improve both fitness and motor competence in children.

A wider use of reproductive and productive styles occurred in IG compared to in CG. These styles differ in terms of the provision of task-related feedback. In the command and practice styles, the educator provides the task-related feedback. In the reciprocal style, another student provides the task-related feedback (observer), while in the self-check styles and inclusion process styles the children assesses his/her own task performance [17].

According to the challenge point theory by Guadagnoli and Lee [53], this differentiation may be useful to adapt the nominal difficulty of the task to the different capacities and learning modalities of each children, making it possible to foster motor competence development.

\subsection{Self-Perception and Enjoyment}

Throughout the final years of the primary school, children start to develop the perception of themselves in relation to their peers. It could be fundamental in determining their future participation in PA. The lack of change in positive self-perception observed in this study suggests that a more specific intervention should be designed to increase this construct in children or that a more specific tool should be used to assess the self-perception of PA [25].

For example, PE students received a criticism according to which they did not always compose balanced game teams (see the results of the semi-structured interviews in the section "children's perception of PE lessons and of primary school classroom teachers or PE students"). According to Ames [56], to avoid unfavourable "questions" and comparisons within the group which may 
emphasize negative self-perceptions of the less skilled children, interventions can be made by creating more balanced competition groups during games. At the same time, to support the advance and progress of less skilled children, the suggestion is to propose collaboration exercises and building heterogeneous groups. The aim of this approach is the establishment of friendly relationships so that the most skillful children can help the less skillful ones. In this way, children can feel calmer and more confident in helping each other, increasing the mutual tolerance during the competitive games. Nevertheless, these competitive activities should be managed with caution and they must be a small percentage of the whole activity.

In addition, the PE students' training should not emphasize only the development of the motor abilities, but has to pay particular attention to further features such as mutual help, attention, discipline, commitment, interest, knowledge of the topics, to preserve a positive self-perception even when a lack of specific motor competence subsists [57].

The improvement in the post-training enjoyment levels suggests that the IG had a more positive experience of PE compared to the CG. Previous research showed that enjoyment is lower when the methodological intervention is mainly represented by a "command" teaching style, which explains the low level of enjoyment noted for the CG, and in which the "command" teaching style was used about $60 \%$ more than in IG (Table 5) [58]. Furthermore, it was observed that a climate based on performance and competition, similar to that used in the CG (see the results of the semi-structured interviews with children in the section "children's perception of PE lessons and of primary school classroom teachers or PE students") can reduce enjoyment and generate a negative attitude toward PE [25]. In contrast, variety and novelty of activities, and the use of multi-styles as the reciprocal style, self-check, inclusion process, guided discovery, and problem-solving involved the students in a significant higher amount of decision-making processes, and in a mastery climate (see the qualitative results of the teacher's behaviour in the sections "video analysis of the PE lessons" and "children's perception of PE lessons and of primary school classroom teachers or PE students"). Altogether, this can be considered a fundamental way to increase enjoyment, positive class climate and motivation during PE [17,25].

\subsection{Amount of Physical Activity}

In the IG, the approach focused on promoting PA was successful in increasing the weekly PA volume (about $+21 \%$ ) whereas no change in PA volume was noted for the CG. These results are in line with those reported by Boyle-Holmes et al. [59] in their study that evaluated a teaching program based on knowledge and the promotion of physical endurance, in addition to motor skills acquisition. A method largely oriented to an MTA approach may contribute to the creation of a mastery climate [25] and lead to an increase in weekly PA [60].

Unfortunately, teachers rarely promote PA during PE lessons [61]. The literature and the outcomes of our study indicate that promotion of PA outside the school should be a fundamental part of teachers' didactic and pedagogical interventions. Furthermore, the increased amount of PA in IG could be linked to the increase in motor competence, as demonstrated in other studies [62].

\subsection{Children's Perception of PE Lessons and of Primary School Classroom Teachers or PE Students}

Dissimilar information emerged from the interviews with the children. Several CG children were dissatisfied with the PE lessons because of the quarrels during games. Game activities play a key role in the development of social attitudes [63]. However, when didactic, organizational, pedagogical, and corrective indications are lacking, games may result in aggressive attitudes or excessive competitiveness. The frequent and autonomous game situations, proposed by teachers, through the learned-initiated teaching style, were not fully appreciated. Moreover, as underlined by Mosston and Ashworth [17], these games situations are appreciated only by the individuals who proposed the game.

Further insights concern endurance activities: the CG negatively perceived endurance activities, whereas the IG found the endurance activities to be highly stimulating and enjoyable exercises. 
As previously highlighted, one example of an endurance activity is the "little train" game, where the leader has to maintain an appropriate running pace for the entire group, even for the less trained individuals. The leader role is assumed in turns by a pupil who assesses the group status and sets the running pace. Runners can freely stop for one or two laps if being particularly tired. The interaction between factors such as information from the body, information from the environment, and support from the group, together with reflection and a certain level of freedom, can explain why the "little train" game and the MTA approach in general are so appreciated by children [64].

A negative aspect of PE emerged in the CG: boredom because of lack of novel activities. Game activities that children normally consider as being fun to play can be perceived as boring and repetitive, while physical exercise may be perceived as enjoyable when proposed as a discovery or a challenge, as the IG experienced in their lessons. Variety and novelty are key elements to foster enjoyment and motivation throughout an activity [54,65].

Appreciation of primary school classroom teachers' and PE students' abilities was higher among the IG children. A few IG children reported that the PE students had trouble managing the class, which could indicate the need to prolong the PE students' training or to better familiarise the PE students with the class [66]. Finally, the CG children mentioned that the primary school classroom teachers were unadapt at leading the games. This lack might be ascribed to the fact that primary school teachers are not specialised in PE teaching.

\subsection{Video Analysis of the PE Lessons and of the Primary School Classroom Teacher or PE Students Self-Perception of the Teaching Styles}

The studies by Sallis et al. [67] served as a basis for video analysis of the didactics of the teachers' intervention. Thanks to the precise content of the activities, starting from the first lessons, the IG were taught the advantages and the features of good practice for health and how to organize PA practice outside school.

The CG lessons were shorter (about 26.8\%) than the IG lessons. This difference suggests that primary school classroom teachers often have a poor consideration for PE and tend to detract time from it, as confirmed by the semi-structured interviews with the children (Figure 4). The resting time taken by the CG was $23.8 \%$ longer than that of the IG, possibly denoting a difficulty of the primary school classroom teachers (CG) to manage the disruptive behaviour of students during PA [67]. In the long run, less time dedicated to PE lessons could have a significantly negative impact on the children's physical literacy development during PE [4]. Regarding action time, the IG spent $6.6 \%$ more time active than the CG. Similarly, the IG dedicated $17.2 \%$ of the time reflecting on the activity, while the CG never spent any time in reflecting. This supports the previous statement that PE is often seen by primary school classroom teachers as play time rather than a learning opportunity.

In the analysis of the teaching styles, the wider range of methods used by the PE students (IG) (Table 5) might have played an important role in fostering the development of motor skills [62]. The teaching approaches in the CG were "command style" and to a lesser extent "learned-initiated". There was an evident discrepancy between the teaching style that the primary school classroom teachers reported and the ones that they effectively employed (Tables 2 and 4). Possible reasons are the lack of PE training of primary school classroom teachers and lack of understanding of the teaching styles [68]. In contrast, the PE students" teaching to the IG used "guided discovery" and "problem-solving" together with "command", "practice" and "reciprocal styles" in their MTA approaches. In this case, there was coherence between the styles the PE students reported (Table 3) and the ones they actually employed (Table 5). 


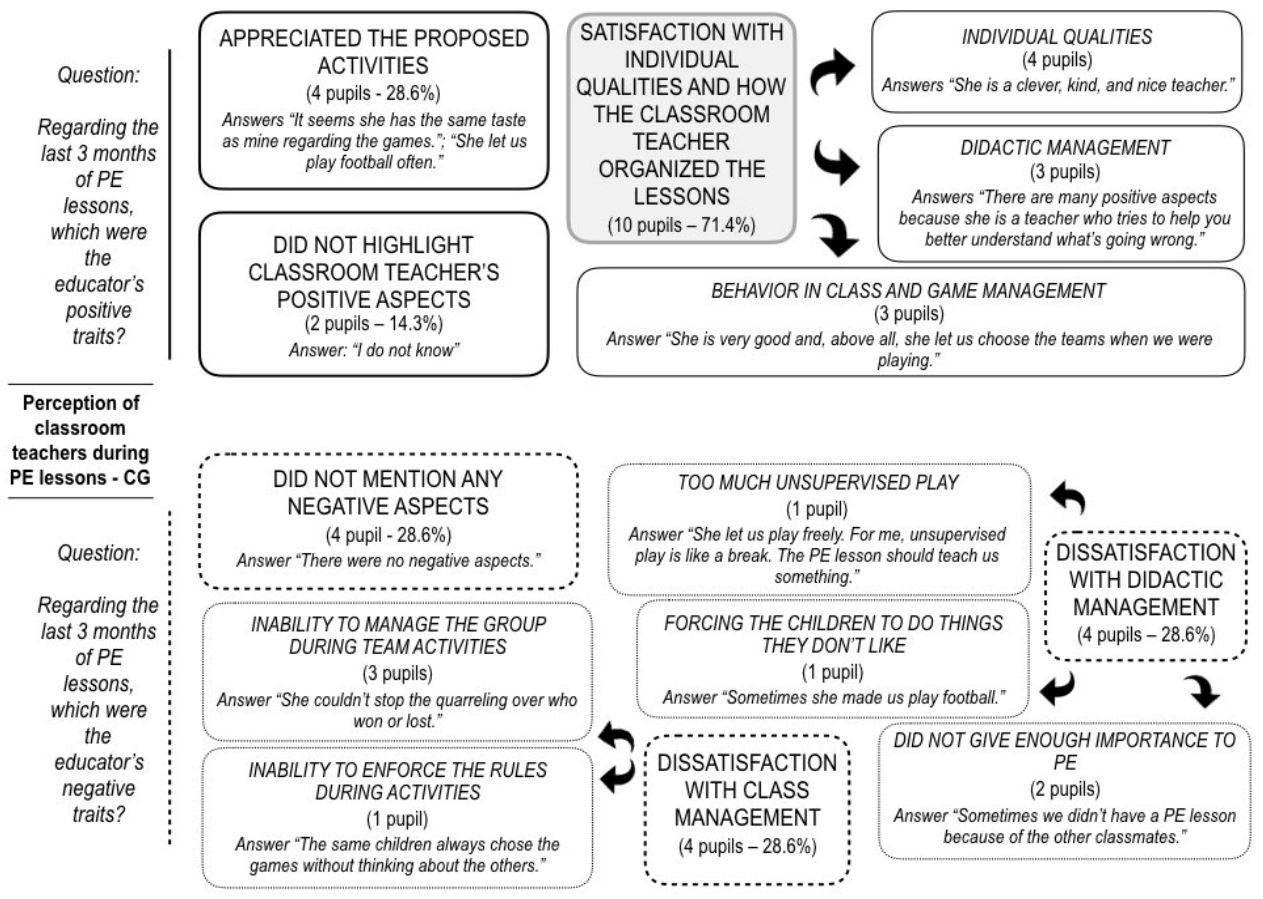

Figure 4. Semi-structured interview responses from the CG children about their perception of primary school teachers during PE lessons.

The literature states that a command style is less complex compared to the teaching styles that directly involve students in critical thinking and decision-making processes [69]. The use of styles as problem-solving, guided discovery, inclusion, self-check, reciprocal, requires practice, adequate activity plans, adequate equipment, reflection on the results, and possible information and feedback from experts [66], as those adopted in the training of PE students.

\subsection{Limitations}

In a monist and holistic approach, the individual is seen as a body and mind forming an indissoluble entity [7]. In this perspective, affective, social, cognitive, physiological and movement competences aspects interact each other influencing how individuals behave in the environment. A teacher might focus his intervention on one of these aspects to affect other components, and therefore the development of an individual as a whole.

Given that PA involves the integration of all the mentioned human aspects and that each individual is a unique and complex system, it is a big challenge for the teacher to find the best way to foster learning in each individual [70].

However, being able to recognise and employ different teaching approaches might facilitate teachers in their challenging jobs.

In light of these considerations, the main limitation of the present study is the inability to discern to which extent every single teaching style contributed to the improvement of a specific motor competence, enjoyment, PA or any other feature assessed.

\subsection{Practical Application}

The MTA, depending on the situation and students' needs, can be proposed in different ways, both with a prevalence of reproductive information and prevalence of productive strategies [54].

As an example, teachers can use reproductive teaching styles to facilitate children's adaptation to a standard performance or to a rule (e.g., when security rules are required to guarantee the learner's safety or when a sport discipline requires highly stereotyped movements). From this teaching style perspective, if the aim of a lesson is to walk on a balance beam maintaining balance, the teacher 
might propose the following progression of tasks: walking on a straight line on the floor; walking on a straight line on a mat in different ways; walking on a line on an elevated surface like a bench; and finally walking on a balance beam. Usually, this approach leads to successful learning outcomes in relative short time and to a precise performance in line with the instructions and the model proposed by the teacher $[17,71]$.

Furthermore, the teacher can propose productive teaching styles to foster creativity and problem-solving when learning outcomes need to be applied in environments and situations characterised by continuous and unpredictable changes. From this teaching perspective, if the aim of a lesson is to walk on a balance beam maintaining balance, the teacher might invite learners to experiment or create different movement solutions to move on various surfaces maintaining balance or to observe and get ideas from the balance strategies that have been adopted by their peers.

In this last approach, learners have a central role in their learning process while teachers facilitate learning by manipulating personal, task and environmental constraints. This teaching approach might require more time for learners to consolidate skills or specific movements, but it has the potential to improve learner's capacity to find different movement solutions to a problem and the capacity to modify the action based on the requirements of the situation [17,71,72].

The ideal teacher should be a reflective teacher; this means being able to combine in the more appropriate fashion the different teaching styles (which compose the MTA) according to the situations to cope with and with the aim to improve good practices and healthy life styles to promote physical literacy [73].

\subsection{Sustainability Education}

The children participating in MTA and reflective practice improved health-related outcomes comprising the fitness level, motor competence, enjoyment and amount of PA confirming that the promotion of high-quality MTA in PE could represent a sustainable approach to preventing healthcare expenses in the future [15].

Furthermore, our findings suggest that introducing MTA and reflective practice in the standard PE programs represents an important step toward the improvement of children's experience during PE and physical literacy promotion. In view of that, teacher should focus on the quality of practices the children experienced, rather than quantity of PA during PE, to foster positive health-related behaviors and physical literacy development in the future [74-76].

From a didactic point of view, the process of physical literacy is accomplished when an individual is educated, instructed and affectively stimulated, in particular: educated by means of the cognitive and cultural aspects of the discipline which facilitate engagement in PA; instructed by means of a technical and practical competence; stimulated by means of fun activities and games.

The choice of a teaching style compared to another one determines completely different results in terms of awareness, motor engagement, and psycho-social interaction [77].

MTA allows modulating the degree of involvement of the different areas of the personality (cognitive, social, affective, and motor) based on the needs of the learners, considering all the physical literacy's domains. In particular, MTA fosters the relationships among the cognitive, motor, and psycho-social functions of the individual, integrating the own motor background with new responses and adaptations [76].

All these processes aim to build up and strengthen the pillars of the physical literacy since the youth. The main purpose is to contribute to the natural practice of PA during the lifespan. A wider attention and specific educational plans both in academic schools of sport and primary education sciences should be taken into account for the dissemination and sustainability of MTA.

\section{Conclusions}

The findings revealed a significant increase in the children's fitness level, motor competence, enjoyment and the amount of PA in the IG compared to those in the CG. Furthermore, the children 
of the IG spent more time being engaged on a task, reflecting on it, and wasted less time during PE compared to the children of the CG. Finally, the children of the IG reported higher levels of satisfaction with PE lessons and teaching styles compared to children of the CG.

The novelty of this study, compared to the previous ones that mainly focused on "how much and what to do" in PE [54], is the change of prospective about "how to do" including how educators teach and how children learn.

In view of our results, we suggest that:

- the integration of different teaching styles, and

- the design of specific protocol to train MTA

could be a valuable strategy to provide learning experiences that are adequately tailored to the needs of children in primary schools and that could have positive effects on different aspects of children physical literacy development to promote healthy lifestyles.

Author Contributions: Conceptualization, P.I.; data curation, M.C.; formal analysis, M.C. and L.C.; investigation, M.C.; methodology, P.I. and G.A.; supervision, P.I. and R.S.; validation, G.A.; writing of the original draft, P.I., M.C., A.B., L.C. and R.S.; writing of review and editing, P.I., M.C., A.B. and R.S. All authors read and approved the final manuscript.

Funding: This research received no external funding.

Acknowledgments: The authors would like to thank the reviewers for their valuable comments that contributed to improve the quality and clarity of this manuscript.

Conflicts of Interest: The authors declare no conflict of interest.

\section{References}

1. Froberg, K.; Andersen, L.B. Mini review: Physical activity and fitness and its relations to cardiovascular disease risk factors in children. Int. J. Obes. 2005, 29 (Suppl. 2), S34-S39. [CrossRef]

2. Saunders, T.J.; Chaput, J.-P.; Tremblay, M.S. Sedentary behaviour as an emerging risk factor for cardiometabolic diseases in children and youth. Can. J. Diabetes 2014, 38, 53-61. [CrossRef] [PubMed]

3. Telama, R.; Yang, X.; Viikari, J.; Välimäki, I.; Wanne, O.; Raitakari, O. Physical activity from childhood to adulthood: A 21-year tracking study. Am. J. Prev. Med. 2005, 28, 267-273. [CrossRef] [PubMed]

4. Dobbins, M.; Husson, H.; DeCorby, K.; LaRocca, R.L. School-based physical activity programs for promoting physical activity and fitness in children and adolescents aged 6 to 18. Cochrane Database Syst. Rev. 2013, 2, CD007651. [CrossRef] [PubMed]

5. World Health Organization. The World Health Report 2007: A Safer Future: Global Public Health Security in the 21st Century; WHO Press: Geneva, Switzerland, 2007.

6. Whitehead, M. The Concept of Physical Literacy. Eur. J. Phys. Educ. 2001, 6, 127-138. [CrossRef]

7. Whitehead, M. Physical Literacy: Throughout the Lifecourse; Taylor \& Francis: London, UK, 2010.

8. Hardy, L.L.; Barnett, L.; Espinel, P.; Okely, A.D. Thirteen-year trends in child and adolescent fundamental movement skills: 1997-2010. Med. Sci. Sports Exerc. 2013, 45, 1965-1970. [CrossRef] [PubMed]

9. Farooq, M.A.; Parkinson, K.N.; Adamson, A.J.; Pearce, M.S.; Reilly, J.K.; Hughes, A.R.; Janssen, X.; Basterfield, L.; Reilly, J.J. Timing of the decline in physical activity in childhood and adolescence: Gateshead Millennium Cohort Study. Br. J. Sports Med. 2018, 52, 1002-1006. [CrossRef] [PubMed]

10. Rhodes, R.E.; Janssen, I.; Bredin, S.S.D.; Warburton, D.E.R.; Bauman, A. Physical activity: Health impact, prevalence, correlates and interventions. Psychol. Health 2017, 32, 942-975. [CrossRef] [PubMed]

11. Tammelin, R.; Yang, X.; Leskinen, E.; Kankaanpaa, A.; Hirvensalo, M.; Tammelin, T.; Raitakari, O.T. Tracking of physical activity from early childhood through youth into adulthood. Med. Sci. Sports Exerc. 2014, 46, 955-962. [CrossRef]

12. Barquera, S.; Pedroza-Tobias, A.; Medina, C.; Hernandez-Barrera, L.; Bibbins-Domingo, K.; Lozano, R.; Moran, A.E. Global overview of the epidemiology of atherosclerotic cardiovascular disease. Arch. Med. Res. 2015, 46, 328-338. [CrossRef]

13. Roetert, E.P.; Jefferies, S.C. Embracing physical literacy. J. Phys. Educ. Recreat. Dance 2014, 85, 38-40. [CrossRef] 
14. Stodden, D.F.; Goodway, J.D.; Langendorfer, S.J.; Roberton, M.A.; Rudisill, M.E.; Garcia, C.; Garcia, L.E. A developmental perspective on the role of motor skill competence in physical activity: An emergent relationship. Quest 2008, 60, 290-306. [CrossRef]

15. Robinson, L.E.; Stodden, D.F.; Barnett, L.M.; Lopes, V.P.; Logan, S.W.; Rodrigues, L.P.; D’Hondt, E. Motor competence and its effect on positive developmental trajectories of health. Sports Med. 2015, 45, 1273-1284. [CrossRef] [PubMed]

16. Rink, J.; Xa, E.; Hall, T.; Xa, J. Research on effective teaching in elementary school physical education. Elementary Sch. J. 2008, 108, 207-218. [CrossRef]

17. Mosston, M.; Ashworth, S. Teaching Physical Education; Benjamin-Cummings Pub Co: San Francisco, CA, USA, 2002.

18. Curtner-Smith, M.D.; Todorovich, J.R.; McCaughtry, N.A.; Lacon, S.A. Urban teachers' use of productive and reproductive teaching styles within the confines of the national curriculum for physical education. Eur. Phys. Educ. Rev. 2001, 7, 177-190. [CrossRef]

19. Jaakkola, T.; Watt, A. Finnish physical education teachers' self-reported use and perceptions of Mosston and Ashworth's teaching styles. J. Teach. Phys. Educ. 2011, 30, 248-262. [CrossRef]

20. Syrmpas, I.; Digelidis, N.; Watt, A. An examination of Greek physical educators' implementation and perceptions of Spectrum teaching styles. Eur. Phys. Educ. Rev. 2016, 22, 201-214. [CrossRef]

21. Jarani, J.; Grøntved, A.; Muca, F.; Spahi, A.; Qefalia, D.; Ushtelenca, K.; Kasa, A.; Caporossi, D.; Gallotta, M.C. Effects of two physical education programmes on health- and skill-related physical fitness of Albanian children. J. Sports Sci. 2016, 34, 35-46. [CrossRef]

22. Byra, M. A review of Spectrum research. In Teaching Physical Education, 5th ed.; Ashworth, M.M.S., Ed.; Benjamin Cummings: San Francisco, CA, USA, 2002; pp. 319-335.

23. Chow, J.Y.; Davids, K.; Hristovski, R.; Araújo, D.; Passos, P. Nonlinear pedagogy: Learning design for self-organizing neurobiological systems. New Ideas Psychol. 2011, 29, 189-200. [CrossRef]

24. Gray, P. Free to Learn: Why Unleashing the Instinct to Play Will Make Our Children Happier, More Self-Reliant, and Better Students for Life; Basic Books: New York, NY, USA, 2013.

25. Morgan, K.; Kingston, K.; Sproule, J. Effects of different teaching styles on the teacher behaviours that influence motivational climate and pupils' motivation in physical education. Eur. Phys. Educ. Rev. 2005, 11, 257-285. [CrossRef]

26. Alrahlah, A. How effective the problem-based learning (PBL) in dental education. A critical review. Saudi Dent. J. 2016, 28, 155-161. [CrossRef] [PubMed]

27. Lutze-Mann, L. Strategies for enhancing student understanding through active engagement (LB113). FASEB J. 2014, 28, LB113.

28. Salvara, M.I.; Jess, M.; Abbott, A.; Bognár, J. A preliminary study to investigate the influence of different teaching styles on pupils' goal orientations in physical education. Eur. Phys. Educ. Rev. 2006, 12, 51-74. [CrossRef]

29. Tombak, B.; Altun, S. The effect of cooperative learning: University example. Eurasian J. Educ. Res. 2016, 16, 173-196. [CrossRef]

30. Tinning, R. Becoming a Physical Education Teacher: Contemporary and Enduring Issues; Pearson Education Australia: Frenchs Forest, N.S.W., Australia, 2001; p. 351.

31. Rink, J. Teaching Physical Education for Learning; McGraw-Hill: New York, NY, USA, 2006; p. 428.

32. Gerney, P.; Dort, A. The Spectrum Applied: Letters from the Trenches. J. Phys. Educ. Recreat. Dance 1992, 63, 36-39. [CrossRef]

33. Ministero dell'Istruzione dell'Università e della Ricerca. Indicazioni nazionali per il curricolo della scuola dell'infanzia e del primo ciclo d'istruzione. In Annali della Pubblica Istruzione; Le Monnier: Firenze, Italy, 2012.

34. Ni Chróinín, D.; Fletcher, T.; O'Sullivan, M. Pedagogical principles of learning to teach meaningful physical education. Phys. Educ. Sport Pedagog. 2018, 23, 117-133. [CrossRef]

35. Winsley, R.J. The suitability of the multistage fitness test to assess children's aerobic fitness. Eur. J. Phys. Educ. 2003, 8, 19-28. [CrossRef]

36. Ulrich, D.A. Test of Gross Motor Development 2nd Edition (TGMD-2); École des sciences de la réadaptation, Sciences de la santé, Université d'Ottawa: Ottawa, ON, Canada, 2004.

37. Barnett, L.M.; Minto, C.; Lander, N.; Hardy, L.L. Interrater reliability assessment using the Test of Gross Motor Development-2. J. Sci. Med. Sport 2014, 17, 667-670. [CrossRef] 
38. Sun, S.-H.; Sun, H.-L.; Zhu, Y.-C.; Huang, L.-C.; Hsieh, Y.-L. Concurrent validity of Preschooler Gross Motor Quality Scale with Test of Gross Motor Development-2. Res. Dev. Disabil. 2011, 32, 1163-1168. [CrossRef]

39. Marsh, H.W.; Shavelson, R. Self-Concept: Its Multifaceted, Hierarchical Structure. Educ. Psychol. 1985, 20, 107-123. [CrossRef]

40. Kaminski, P.L.; Shafer, M.E.; Neumann, C.S.; Ramos, V. Self-concept in Mexican American girls and boys: Validating the Self-Description Questionnaire-I. Cultur. Divers. Ethnic Minor. Psychol. 2005, 11, 321-338. [CrossRef] [PubMed]

41. Carraro, A.; Young, M.C.; Robazza, C. A contribution to the validation of the Physical Activity Enjoyment Scale in an Italian sample. Soc. Behav. Pers. 2008, 36, 911-918. [CrossRef]

42. Motl, R.W.; Dishman, R.K.; Saunders, R.; Dowda, M.; Felton, G.; Pate, R.R. Measuring enjoyment of physical activity in adolescent girls. Am. J. Prev. Med. 2001, 21, 110-117. [CrossRef]

43. Crocker, P.R.; Bailey, D.A.; Faulkner, R.A.; Kowalski, K.C.; McGrath, R. Measuring general levels of physical activity: Preliminary evidence for the Physical Activity Questionnaire for Older Children. Med. Sci. Sports Exerc. 1997, 29, 1344-1349. [CrossRef] [PubMed]

44. Lincoln, Y.S.; Guba, E.G. Naturalistic Inquiry; SAGE: Beverly Hills, CA, USA, 1985; p. 422.

45. Hill, C.E.; Knox, S.; Thompson, B.J.; Williams, E.N.; Hess, S.A.; Ladany, N. Consensual qualitative research: An update. J. Couns. Psychol. 2005, 52, 196. [CrossRef]

46. Corbin, J.; Strauss, A. Basics of Qualitative Research: Techniques and Procedures for Developing Grounded Theory; Sage Publications: Thousand Oaks, CA, USA, 1998.

47. Ashworth, S. Description Inventory of Landmark Teaching Styles: A Spectrum Approach. Available online: http:/ / www.spectrumofteachingstyles.org/pdfs/literature/Ashworth2004_Description_Inventory_ Of_Landmark.pdf (accessed on 15 November 2018).

48. SueSee, B.; Edwards, K.; Pill, S.; Cuddihy, T. Self-reported teaching styles of Australian senior physical education teachers. Curric. Perspect. 2018, 38, 41-54. [CrossRef]

49. Curtner-Smith, M.D. Instrument for Identifying Teaching Styles (IFITS). Available online: http://www. spectrumofteachingstyles.org/pdfs/literature/CurtnerSmith2001_IFITS.pdf (accessed on 15 November 2018).

50. Cohen, J. Statistical Power Analysis for the Behavioral Sciences; L. Erlbaum Associates: Hillsdale, NJ, USA, 1988; p. 594.

51. Hellison, D.R.; Templin, T.J. A Reflective Approach to Teaching Physical Education; Human Kinetics: Champaign, IL, USA, 1991.

52. Strong, W.B.; Malina, R.M.; Blimkie, C.J.; Daniels, S.R.; Dishman, R.K.; Gutin, B.; Hergenroeder, A.C.; Must, A.; Nixon, P.A.; Pivarnik, J.M.; et al. Evidence based physical activity for school-age youth. J. Pediatr. 2005, 146, 732-737. [CrossRef] [PubMed]

53. Guadagnoli, M.A.; Lee, T.D. Challenge point: A framework for conceptualizing the effects of various practice conditions in motor learning. J. Mot. Behav. 2004, 36, 212-224. [CrossRef]

54. Pesce, C.; Faigenbaum, A.; Crova, C.; Marchetti, R.; Bellucci, M. Benefits of multi-sports physical education in the elementary school context. Health Educ. J. 2012, 72, 326-336. [CrossRef]

55. Pesce, C.; Croce, R.; Ben-Soussan, T.D.; Vazou, S.; McCullick, B.; Tomporowski, P.D.; Horvat, M. Variability of practice as an interface between motor and cognitive development. Int. J. Sport Exerc. Psychol. 2016, 1-20. [CrossRef]

56. Ames, C.P. Achievement goals, motivational climate, and motivational processes. In Motivation in Sport and Exercise; Robertts, G.C., Ed.; Human Kinetics: Champaign, IL, USA, 1992; pp. 161-176.

57. Eggleston, M.; Hanger, N.; Frampton, C.; Watkins, W. Coordination difficulties and self-esteem: A review and findings from a New Zealand survey. Aust. Occup. Ther. J. 2012, 59, 456-462. [CrossRef]

58. Boyce, B.A. The effects of three styles of teaching on university students' motor performance. J. Teach. Phys. Educ. 1992, 11, 389-401. [CrossRef]

59. Boyle-Holmes, T.; Grost, L.; Russell, L.; Laris, B.A.; Robin, L.; Haller, E.; Potter, S.; Lee, S. Promoting elementary physical education: Results of a school-based evaluation study. Health Educ. Behav. 2010, 37, 377-389. [CrossRef] [PubMed]

60. Parish, L.E.; Treasure, D.C. Physical activity and situational motivation in physical education: Influence of the motivational climate and perceived ability. Res. Q. Exerc. Sport 2003, 74, 173-182. [CrossRef] [PubMed] 
61. Kelder, S.H.; Mitchell, P.D.; McKenzie, T.L.; Derby, C.; Strikmiller, P.K.; Luepker, R.V.; Stone, E.J. Long-term implementation of the CATCH physical education program. Health Educ. Behav. 2003, 30, 463-475. [CrossRef] [PubMed]

62. Barnett, L.M.; Morgan, P.J.; van Beurden, E.; Beard, J.R. Perceived sports competence mediates the relationship between childhood motor skill proficiency and adolescent physical activity and fitness: A longitudinal assessment. Int. J. Behav. Nutr. Phys. Act. 2008, 5, 40. [CrossRef] [PubMed]

63. Goldberger, M.; Gerney, P.; Chamberlain, J. The Effects of Three Styles of Teaching on the Psychomotor Performance And Social Skill Development of Fifth Grade Children. Res. Q. Exerc. Sport 1982, 53, 116-124. [CrossRef] [PubMed]

64. Nicholls, J.G. Achievement motivation: Conceptions of ability, subjective experience, task choice, and performance. Psychol. Rev. 1984, 91, 328. [CrossRef]

65. Schunk, D.H.; Meece, J.L. Student Perceptions in the Classroom; Routledge: London, UK, 1992; p. 380.

66. Guskey, T.R. Staff development and the process of teacher change. Educ. Res. 1986, 15, 5-12. [CrossRef]

67. Sallis, J.F.; McKenzie, T.L.; Alcaraz, J.E.; Kolody, B.; Faucette, N.; Hovell, M.F. The effects of a 2-year physical education program (SPARK) on physical activity and fitness in elementary school students. Sports, Play and Active Recreation for Kids. Am. J. Public Health 1997, 87, 1328-1334. [CrossRef] [PubMed]

68. Emmanouel, C.; Zervas, Y.; Vagenas, G. Effects of four physical education teaching methods on development of motor skill, self-concept, and social attitudes of fifth-grade children. Percept. Mot. Skills 1992, 74, 1151-1167. [CrossRef] [PubMed]

69. White, P.T. Perceptions of Physical Education Majors and Faculty Members Regarding the Extent of Use of and Exposure to Mosston's: Mosston and Ashworth's Spectrum of Teaching Styles; University of Iowa: Iowa City, IA, USA, 1998; p. 646.

70. Bernshteĭn, N.A. The Co-Ordination and Regulation of Movements; Pergamon Press: Oxford, UK, 1967.

71. Lee, M.C.Y.; Chow, J.Y.; Komar, J.; Tan, C.W.K.; Button, C. Nonlinear pedagogy: An effective approach to cater for individual differences in learning a sports skill. PLoS ONE 2014, 9, e104744. [CrossRef] [PubMed]

72. Chow, J.Y.; Atencio, M. Complex and nonlinear pedagogy and the implications for physical education. Sport Educ. Soc. 2014, 19, 1034-1054. [CrossRef]

73. Burrows, L.; Macdonald, D.; Wright, J. Critical Inquiry and Problem Solving in Physical Education: Working with Students in Schools; Taylor \& Francis: London, UK, 2013.

74. Gallahue, D.; Ozmun, J.; Goodway, J.D. Understanding Motor Development: Infants, Children, Adolescents, Adults; McGraw Hill: New York, NY, USA, 2012.

75. Janssen, I.; Leblanc, A.G. Systematic review of the health benefits of physical activity and fitness in school-aged children and youth. Int. J. Behav. Nutr. Phys. Act. 2010, 7, 40. [CrossRef] [PubMed]

76. Poitras, V.J.; Gray, C.E.; Borghese, M.M.; Carson, V.; Chaput, J.P.; Janssen, I.; Katzmarzyk, P.T.; Pate, R.R.; Connor Gorber, S.; Kho, M.E.; et al. Systematic review of the relationships between objectively measured physical activity and health indicators in school-aged children and youth. Appl. Physiol. Nutr. Metab. 2016, 41, S197-S239. [CrossRef]

77. Garn, A.; Byra, M. Psychomotor, cognitive, and social development Spectrum style. Teach. Elementary Phys. Educ. 2002, 13, 8-13.

(C) 2019 by the authors. Licensee MDPI, Basel, Switzerland. This article is an open access article distributed under the terms and conditions of the Creative Commons Attribution (CC BY) license (http:// creativecommons.org/licenses/by/4.0/). 